\title{
Análisis de la autoría en la producción científica sobre pintura rupestre postpaleolítica de los estilos levantino y esquemático en España (1907-2010)
}

\author{
Miguel Ángel Mateo Saura * \\ Isidoro Gil Leiva ** \\ Antonio Pulgarín Guerrero ***
}

Artículo recibido:

22 de enero de 2014.

Artículo aceptado:

9 de octubre de 2014.

\section{RESUMEN}

A más de un siglo de investigación sobre la pintura rupestre postpaleolítica en España, que ha llevado a una producción científica que supera los 2000 registros, se lleva a cabo un estudio para evaluar su rendimiento durante el periodo 1907-2010. Se presentan los resultados obtenidos tras el análisis de la productividad de los autores, de la colaboración científica, del papel de la autoría extranjera en la producción científica y de la estructura y dinámica de los grupos de investigación. Se concluye que la investigación sobre la pintura rupestre postpaleolítica en España sigue descansando en

\footnotetext{
* Instituto de Estudios Albacetenses Don Juan Manuel, España. mateosaura@regmurcia.com

** Universidad de Murcia, España. isgil@um.es

*** Universidad de Extremadura, Badajoz, España. pulgarin@alcazaba.unex.es
} 
el trabajo individual y en autores independientes que carecen de adscripción institucional.

Palabras clave: Bibliometría; Autores; Colaboración Científica; Prehistoria; Pintura Rupestre; Pintura Postpaleolítica; Arte Levantino; Pintura Esquemática.

\section{Abstract}

Analysis of the authorship of the scientific output on Levantine and schematic post-Paleolithic rock painting in Spain (1907-2010)

Miguel Ángel Mateo-Saura, Isidoro Gil-Leiva and Antonio Pulgarín-Guerrero

The body research comprised of more than two-thousand titles on post-Paleolithic cave art in Spain spanning the one-hundred and three years (1907-2010) is examined in terms of author productivity, collaboration patterns, foreign authorship, and the structural dynamics of scientific collaboration. The study concludes that research in the field of post-Paleolithic cave painting continuous to rely on individual authors and authors not associated with any institutional organ.

Keywords: Bibliometrics; Authors; Scientific Cooperation; Prehistory; Rock Painting; Post-Paleolithic Painting; Levantine Art; Schematic Painting.

\section{INTRODUCCIÓN}

$\mathrm{T}$

ras el arte rupestre paleolítico, que ha estado vigente durante casi 25 milenios, en España se desarrollan otros horizontes gráficos y culturales que, englobados en el epígrafe general de "arte rupestre postpaleolítico", están asociados a contextos sociales, culturales y económicos variados. Los dos estilos postpaleolíticos principales son el arte rupestre levantino, cuya autoría es aún hoy día objeto de controversia, si bien la mayor parte de los investigadores lo relacionan con los últimos grupos de cazadores del Meso- 
lítico (milenios X-IV a. de n. e.), y la pintura rupestre esquemática, coligada a los primeros grupos productores del neolítico peninsular (milenios IV-III a. de n. e.).

Mientras que el arte levantino se desarrolla en las sierras prelitorales de la vertiente mediterránea de la península ibérica, desde Lérida y Huesca por el norte hasta el interior de Jaén y de Almería por el sur, la pintura rupestre esquemática alcanza una mayor dispersión geográfica al ocupar la mayor parte del territorio peninsular, desde la fachada mediterránea hasta la atlántica y desde las tierras sureñas de Cádiz hasta los sectores más norteños de Castilla-León.

Aunque ambos estilos se asocian a grupos desiguales en lo económico y en lo social (Mateo Saura, 2009), es cierto que muestran numerosas convergencias que han servido para evaluar eventuales relaciones entre los dos horizontes culturales (Mateo Saura, 2001). La mayor parte de las representaciones de los dos estilos se sitúan en las paredes de pequeños abrigos rocosos abiertos a la luz solar directa, formados en el relieve cárstico a partir de la degradación meteórica de la roca caliza por la filtración del agua y la acción del viento. En la vertiente mediterránea peninsular, área en la que coinciden el arte levantino y la pintura esquemática, es frecuente encontrar representaciones de los dos estilos conviviendo en una misma covacha. El análisis de algunos rasgos de las covachas, tales como la tipología de los emplazamientos, su orientación y su altitud, o la propia disposición de las representaciones en los abrigos, arroja unos resultados muy próximos entre los dos estilos.

También advertimos una notable similitud en otros detalles de tipo técnico. Sucede con la composición de la pintura, la misma para los dos, aunque los estudios realizados al respecto han sido muy limitados (Hernanz Gismero y Ruiz López, 2012; Montes Bernández y Cabrera Garrido, 1992; Ripoll Perelló, 1961; Roldán García, 2009, 2012); en los esquemas de representación, en los que se recurre a unos modelos fáciles de identificar, reducidos a sus líneas básicas y presentados desde una perspectiva que clarifique su identificación; y en el empleo de la línea como pilar fundamental de los procesos de ejecución, en su función como definidora de la forma. El aspecto de la línea difiere de uno a otro horizonte: mientras que en el arte levantino se trata de una línea de escaso grosor y con bordes bien definidos, en la pintura esquemática, en general, el trazo muestra unas mayores dimensiones y unos perfiles más descuidados. El color utilizado mayoritariamente en los dos estilos es el rojo, aunque el negro también tiene una presencia destacada. Con carácter local, en el arte levantino de la comarca de Albarracín, en Teruel, documentamos algunas representaciones de color blanco. El tamaño de los motivos se mantiene dentro de unos límites que podríamos situar entre 5 y 
$50 \mathrm{~cm}$, si bien no faltan representaciones que son auténticas miniaturas de unos pocos milímetros y otras que llegan a superar el metro de longitud.

El principal rasgo diferenciador entre los dos horizontes gráficos se determina por el lenguaje expresivo utilizado en cada uno de ellos. Mientras que el arte levantino está revestido de un naturalismo que permite el reconocimiento temático de los diferentes motivos pintados, de tal forma que un arquero o un ciervo se reconocen como tales por la expresión clara de sus rasgos morfológicos, en la pintura esquemática la abstracción a la que han sido sometidos los diversos motivos es tal que no sólo se reducen a sus líneas formales básicas, como sucede con los humanos y los animales, sino que se reinterpretan y se convierten en signos codificados, no identificables para todos aquellos que, como nosotros, desconocen el código que articula el proceso de comunicación que tiene a la pintura como vehículo de trasmisión de un mensaje dado.

Este grado de abstracción es el que provoca las diferencias entre ambos horizontes en lo que a la iconografía se refiere. El arte levantino está protagonizado por las figuras humanas y las de animales, cuya combinación da lugar a narrativas escenas de caza, pero también encontramos representaciones humanas formando otro tipo de escenas, entre ellas enfrentamientos bélicos entre bandas, recolección, parejas de mujeres, aglomeraciones de arqueros o grupos de humanos sin una función que nos sea conocida. Las figuras animales, al margen de las composiciones cinegéticas, pueden aparecer aisladas formando manadas sin intervención humana. En ocasiones, una única representación animal constituye todo el contenido pictórico de un abrigo. En el arte esquemático encontramos también las categorías iconográficas de humanos y de animales, con algunas escenas de caza y de ganadería, pero a éstas se suma el heterogéneo grupo de los signos que en la mayoría de los casos son interpretados a partir de su parecido formal con elementos que a nosotros nos son conocidos, pero sin que lleguemos a reconocer su auténtica identidad original.

En este contexto general, a lo largo de los más de 100 años de investigación sobre la pintura rupestre postpaleolítica española, puede que la autoría sea uno de los ámbitos que haya experimentado una evolución más sensible. Quizás uno de los aspectos que mejor lo refleje sea el que concierne a la formación académica de los investigadores. Si desde comienzos del siglo XX, momento en que la arqueología se encontraba en sus albores como disciplina científica, y hasta su primera mitad la investigación del novedoso arte prehistórico estaba en manos de sacerdotes, caso de Henri Breuil o de Hugo Obermaier; de geólogos, como Eduardo Hernández Pacheco, o de personajes vinculados a las bellas artes, como Juan Cabré o Juan Bautista Porcar, desde la 
década de los sesenta del siglo pasado el protagonismo lo van a asumir los arqueólogos y prehistoriadores de forma paralela a la instauración de la especialidad de Prehistoria, Arqueología e Historia Antigua en las universidades españolas. En estos últimos años, una concepción más amplia del arte prehistórico, en la que ha dejado de verse como un fenómeno exclusivamente estético para implicar también factores técnicos, ideológicos y simbólicos, así como la importancia alcanzada dentro de su proceso de estudio por facetas relacionadas con los procedimientos técnicos de elaboración de la pintura o de su reproducción gráfica, han posibilitado que profesionales provenientes de ámbitos científicos muy dispares como la física, la química, la biología o la informática se incorporen a la investigación.

Es un hecho contrastable que la mayor parte de la producción científica actual es, con excepciones, el resultado de la labor de equipos de investigación. Variadas son las motivaciones que justificarían el desarrollo de un trabajo en común, entre las que han destacado compartir costos, favorecer el desarrollo de investigaciones más complejas o permitir el acceso a recursos que no sería posible en un trabajo individual (Russell, Madera Jaramillo y Ainsworth, 2009; Valenciano et al., 2010; Zulueta, Cabrero y Bordons, 1999). En esta línea, Beaver y Rosen (1978) apuntan un extenso catálogo de motivos para esta colaboración entre los que, además de los señalados, estarían el acceso a determinadas habilidades o a equipos técnicos especiales como medio para mejorar la eficacia en el uso del tiempo, para adquirir experiencia, para multiplicar la capacitación, para superar un aislamiento intelectual e incluso para preparar discípulos. Sea una motivación u otra, entre las consecuencias de la colaboración científica se encontrarían, a priori, su incidencia positiva en la productividad de los investigadores y la mayor visibilidad que adquieren los trabajos realizados en equipo.

La colaboración científica es, sin duda, una de las señas de identidad de la ciencia moderna. El propio Price (1963) vaticinó que a finales del siglo XX el trabajo individual habría desaparecido a favor de la colaboración, proponiendo incluso un índice de colaboración de 2.5 firmas/trabajo. Aunque el grado de colaboración científica sí ha aumentado considerablemente en el ámbito de las ciencias experimentales, en el de las humanidades y las ciencias sociales, en general, todavía se está lejos de alcanzar los índices previstos por Price (Over, 1982). En todo caso, la colaboración se convierte en exponente del grado del profesionalización de la comunidad científica (Sancho, 1990) y en el reflejo del apoyo económico a la ciencia por cuanto la inversión favorece la formación de equipos (Agulló Martínez y Aleixandre Benavent, 1999).

En el contexto de un análisis bibliométrico de la producción científica sobre la pintura rupestre postpaleolítica española de los estilos levantino y 
esquemático durante el periodo 1907-2010, la autoría constituye, junto a la producción científica misma, la otra cara de una misma moneda. Si los indicadores bibliométricos proporcionan, en conjunto, información sobre el tamaño, el crecimiento, la evolución, la visibilidad y la estructura del proceso investigador (Agulló Martínez, 1998; Bordons y Zulueta, 1999; Maltrás Barba, 2003; Terrada, 1971, 1973), los de producción, basados en la medición de la producción científica (López Piñero y Terrada, 1992), determinarán aspectos tan concretos como el crecimiento de la ciencia en cualquiera de sus ámbitos y la evolución cronológica de la producción científica, pero también la productividad de los autores, la colaboración entre ellos o entre instituciones y la estructura y dinámica de los grupos que producen y consumen los documentos (Bordons y Zulueta, 1999; González de Dios, Moya y Mateos, 1997; Sancho, 1990).

Analizar la autoría sobre la pintura rupestre postpaleolítica en España durante el periodo 1907-2010 y la estructura de los grupos que producen los documentos desde parámetros bibliométricos constituye el objetivo de nuestro trabajo.

\section{Material y MÉTOdo}

Dada la ausencia de una única base de datos referencial que reuniese todos los documentos publicados sobre la materia, para la realización de este análisis se ha recurrido a la consulta de diversas fuentes de información. Los recursos consultados son los siguientes: base de datos del ISBN para libros y monografías, base de datos TESEO para tesis doctorales, base de datos ISOC del CSIC para artículos científicos y comunicaciones a congresos, base de datos Dialnet, base de datos Web of Science, el fondo bibliográfico Corpus de Pintura Rupestre Levantina del Instituto de Historia del CSIC, el catálogo de la Biblioteca de Humanidades de la Universidad de Murcia y el catálogo de la Biblioteca del Centro de Arte Rupestre de Moratalla (Murcia). De igual modo, la lectura continuada de artículos científicos sobre la materia objeto de estudio a lo largo de estas décadas y una especial atención al apartado de bibliografía de los mismos proporcionaron un importante número de referencias.

Para la consulta de los catálogos y las bases de datos nacionales e internacionales mencionadas se empleó la terminología propia del arte rupestre, como "arte rupestre", "pintura rupestre", "arte levantino", "pintura levantina”, "arte esquemático" o "pintura esquemática”. Estos términos fueron usados para recuperar documentos que estuvieran presentes en los campos Materia, 
Título, Resumen; cuando no se recuperaron documentos o eran pocos se utilizó también la opción Cualquier campo.

Con la extensa bibliografía usada para la elaboración de la memoria de licenciatura de Mateo Saura (1992) y con los documentos provenientes de las consultas a los diferentes recursos mencionados se elaboró una base de datos en Microsoft Access compuesta por 2186 registros bibliográficos. Los últimos documentos se ingresaron a dicha base de datos el 31 de marzo de 2011. ${ }^{1}$

La base de datos elaborada ad boc con los 2186 documentos se estructuró con aquellos campos que resultaban de interés para nuestros propósitos. Creada la base de datos y volcados en ella los registros hallados se procedió a homogeneizar los datos, proceso en el que resultó significativa la identificación segura de la autoría de los trabajos. Es frecuente que aun dentro de una base de datos un mismo autor pueda aparecer nombrado de distinta forma, por ejemplo, suele ocurrir que no se indique el segundo apellido o que el nombre quede abreviado en exceso y no se señale la segunda inicial si se trata de un nombre compuesto. Esta circunstancia plantea la duda de que todas esas variantes se refieran a un mismo autor o que se correspondan con otros tantos autores como variantes hay.

Hemos pretendido unificar todos los autores con sus dos apellidos y el nombre, para lo que hemos consultado directamente los propios documentos que planteaban dudas, cotejándolos entre sí y con el conjunto, para tratar de encontrar alguna coincidencia que nos orientara en un sentido $u$ otro. Algunos de los indicios utilizados son la concurrencia en un área geográfica o en un mismo yacimiento de estudio, la coincidencia en los centros de trabajo o la eventual pertenencia a un grupo de colaboración que suela firmar los trabajos conjuntamente. Para aquellos casos en los que no hemos podido hacer una consulta manual o en los que, a pesar de ésta, todavía carecemos de datos objetivos que ayuden a esclarecer la cuestión, utilizamos el criterio seguido en otros trabajos (Abad Pérez, 1987; Miguel Dasit, 2003) y computamos como autores distintos las diferentes variantes registradas. Asimismo, las abreviaturas "y otros", "et alii" o "et al." han sido eliminadas y sustituidas por los apellidos y el nombre completo de todos los autores firmantes.

Para el estudio de la productividad científica de los autores, el indicador más sencillo (y quizás por ello al que se suele recurrir con mayor frecuencia) es el recuento del número de firmas de los documentos. A partir de éste es un hecho constatado por la mayor parte de los estudios bibliométricos efectuados en los distintos campos de la ciencia que, junto a un número relativamente pequeño de autores muy productivos que son responsables de un alto 
porcentaje de trabajos, convive un destacable número de autores ocasionales que contribuyen de manera muy limitada a la producción total, al margen de considerar que si bien se puede alegar que una mayor productividad no tiene por qué conllevar necesariamente mayor notabilidad, también se ha constatado una estrecha correlación entre productividad y relevancia científica. El primero que se percató de esta realidad y la formuló en términos matemáticos fue Lotka (1926), quien tras cotejar la distribución de frecuencias de la productividad científica de 8216 autores y analizar la distribución de las frecuencias verificó que, partiendo de la unidad de un trabajo publicado, conforme aumentaba el número de trabajos publicados por autor disminuía de una forma regular el número de autores. En nuestro trabajo hemos verificado el cumplimiento de la ley de Lotka siguiendo la metodología propuesta por Pao (1985) y Nicholls (1986).

También hemos calculado el índice de productividad propuesto por Price (1963) a partir del logaritmo decimal del número de publicaciones de los autores, que permite delimitar a lo más productivos entre grupos de autores poco productivos, medianos productores y autores élite, tomando como referencia el índice de productividad del autor cuya posición en la distribución de autores se corresponda con la raíz cuadrada del número total de autores. Íntimamente ligado al índice de productividad, hemos calculado también el índice de transitoriedad, definido por el número de autores ocasionales que publican un solo trabajo (Price y Gürsey, 1976), que nos permitirá valorar el grado de madurez y consolidación de la actividad científica en esta área de estudio.

La colaboración científica, que puede producirse por medios tan variados como la publicación de documentos en coautoría, la comunicación informal de ideas y proyectos en reuniones y congresos o el intercambio epistolar, resulta en ocasiones difícil de medir. Quizás por ello la colaboración más fácilmente cuantificable es aquella basada en el análisis de la coautoría. El indicador que nos proporciona la información es el índice de firmas/trabajo, o índice de colaboración en terminología de Lawani (1986). Asimismo, del análisis de la colaboración a partir de la autoría múltiple podemos conocer la participación de autores extranjeros en la investigación de la pintura rupestre postpaleolítica española y la publicación de resultados por parte de autores españoles en el extranjero, siendo ambos indicadores bastante fiables acerca del grado de internacionalización de la materia de estudio.

Consecuencia directa de la colaboración científica es la formación de grupos de investigación, que se relacionan comúnmente con lo que Price (1963) denominó como colegios invisibles, entendidos como grupos de científicos que investigan sobre los mismos temas en lugares diferentes, a veces muy distantes, e intercambian información por medios distintos a la comunicación 
impresa convencional. La mayor parte de los trabajos bibliométricos que abordan el análisis de redes lo hacen a partir del estudio de las citas de las publicaciones, las cuales se convierten en la base para el establecimiento de una estructura de relaciones entre los científicos. Sin embargo, las revistas españolas no están indizadas, salvo alguna puntual excepción, en las bases de datos internacionales, con la consiguiente ausencia en los citation index de referencia, lo que invalida este método de trabajo. Por ello hacemos un acercamiento a los grupos de colaboración a partir de la propia coautoría.

Para la delimitación de estos grupos y la incorporación de los autores colaboradores partimos de la metodología usada en Bordons, Cabrero y Barrigón (1995) y Zulueta, Cabrero y Bordons (1999): se considera como investigador principal al autor más productor; este investigador principal debe haber publicado, como mínimo, un trabajo al año durante el periodo analizado; para que un autor pueda ser asignado a un grupo debe haber firmado el $60 \%$ de su producción con el cabeza visible del grupo; que los autores ocasionales (1-2 publicaciones) no se asignen a ningún grupo; un grupo debe estar formado al menos por tres autores y los grupos establecidos, al no responder a criterios institucionales sino a criterios de coautoría, pueden incluir autores pertenecientes a distintos centros. No obstante, por las características privativas que ofrecen nuestros datos nos hemos visto obligados a efectuar una adaptación particular de alguno de estos criterios generales, puesto que si estimamos como criterio de exclusión el que un investigador tenga años en blanco en su trayectoria científica quedarían fuera varios de los autores más productores, al tiempo que si eliminamos a los autores ocasionales, cuyo porcentaje supera el 75 \% (Mateo Saura, 2013), y aquellos otros cuya producción en coautoría con el cabeza visible del grupo no alcanza el umbral del $60 \%$, ofreceríamos una visión parcial e irreal de la colaboración científica sobre la pintura rupestre postpaleolítica en España.

Para conocer el grado de cohesión de los grupos calculamos la densidad a partir de la relación entre el número de enlaces establecidos en cada grupo y el número de enlaces posibles entre los miembros de los mismos (Otte y Rousseau, 2002; Valderrama et al., 2007; Valenciano et al., 2010). Por último, debemos mencionar que para la representación gráfica de estas redes empleamos el software Pajek (Batagelj y Mrvar, 2007).

\section{RESUlTADOS Y DISCUSIÓN}

La tipología documental de los 2186 trabajos recopilados sobre la pintura rupestre postpaleolítica de los estilos levantino y esquemático entre 1907 y 
2010, publicados tanto en España como en el extranjero, que constituyen la base de nuestro estudio, se distribuyen en 1208 artículos (55.26 \%), 421 comunicaciones a congresos (19.25\%), 248 capítulos de obras colectivas $(11.34 \%), 218$ monografías (9.97\%), 52 notas $(2.37 \%), 23$ tesis doctorales $(1.05 \%)$ y 16 memorias de licenciatura $(0.73 \%)$. Esta variada tipología documental tiene su incidencia en diversos aspectos de la propia autoría, sobre todo en lo que tiene relación con las pautas de colaboración. Hay tipos de documentos que, por su naturaleza, son de una sola firma, como las tesis doctorales y las memorias de licenciatura; otros pueden mostrar una mayor preferencia hacia el trabajo individual, como pueden ser las monografías o los capítulos de libro; pero en el caso de las comunicaciones a congresos y, sobre todo, de los artículos de revista, se trata de formatos en los que a priori tendría mejor cabida un trabajo en coautoría. En todo caso, como queda reflejado en el apartado correspondiente de la colaboración, en la disciplina objeto de análisis e independientemente del formato de edición elegido sigue siendo muy acentuada la tendencia hacia la firma individual de los documentos.

\section{Estudio de la productividad de los autores}

Los 2186 documentos analizados han sido realizados por 846 autores. De ellos, 484 sólo han publicado un trabajo, lo que supone el $57.21 \%$ del conjunto de autores, mientras que 130 (15.36 \%) firman 2 trabajos. Otros 63 autores (7.44 \%) publican 3 documentos, 29 (3.42\%) firman 4 publicaciones y 19 investigadores $(2.24 \%)$ realizan hasta 5 trabajos. Desde aquí, el número de autores que cuentan con un mayor número de publicaciones va descendiendo gradualmente hasta llegar a un grupo de 12 autores superproductores (1.41\%), en terminología de Martínez Fernández (1996), que publican $\geq 40$ trabajos, de entre los cuales hay 2 autores que firman 92 y 93 documentos, respectivamente, y uno, Antonio Beltrán Martínez, con 179 publicaciones (Tabla 1).

Tabla I. Distribución de trabajos por autores

\begin{tabular}{|c|c|c|}
\hline Trabajos & Autores & \% autores \\
\hline 1 & 484 & 57.21 \\
\hline 2 & 130 & 15.36 \\
\hline 3 & 63 & 7.45 \\
\hline 4 & 29 & 3.43 \\
\hline 5 & 19 & 2.24 \\
\hline $6-10$ & 57 & 6.74 \\
\hline $11-15$ & 23 & 2.72 \\
\hline $16-20$ & 12 & 1.42 \\
\hline
\end{tabular}




\begin{tabular}{|c|c|c|}
\hline $21-25$ & 9 & 1.06 \\
\hline $26-30$ & 6 & 0.70 \\
\hline $31-35$ & 1 & 0.11 \\
\hline $36-40$ & 3 & 0.35 \\
\hline$\geq 41$ & 12 & 1.41 \\
\hline Total & 846 & 100 \\
\hline
\end{tabular}

De acuerdo con el índice de productividad obtenido como referencia en nuestra distribución de autores, que es de 1.32 y corresponde a Jesús Vicente Picazo Millán, autor que ocupa la posición 29 en dicha distribución $(\sqrt{846})$, podemos delimitar un primer grupo de pequeños productores, aquellos que publican un solo trabajo y cuyo índice de productividad es igual a 0. Está integrado por 484 autores $(57.21 \%$ ), a quienes se debe el $14.45 \%$ de la producción. Un segundo grupo, el de los medianos productores (entre 2 y 20 trabajos), está formado por 333 autores (39.36\%), que tienen la responsabilidad del $47.95 \%$ de los documentos. Y, por último, el grupo de los grandes productores ( $\geq 21$ publicaciones), cuyo índice de productividad es igual o mayor que 1.32 , y que en nuestro estudio está integrado por 29 autores $(3.42 \%)$, responsables del $37.60 \%$ de las publicaciones.

Otras conclusiones que arrojan estos datos son que el índice de productividad máximo (2.25) corresponde a un único autor, al citado Antonio Beltrán Martínez, que ha publicado 179 trabajos, y que el índice de transitoriedad, determinado por el número de autores ocasionales que publican un solo trabajo (Price y Gürsey, 1976), es del 57.21 \%. Este último índice resulta de gran interés por tratarse de un indicador muy fiable del grado de consolidación de la actividad científica en un área concreta (Shubert y Glänzel, 1991). En nuestro caso es un porcentaje relativamente alto, aunque no llega al de otras disciplinas en las que se supera incluso el $80 \%$ de transitoriedad (Álvarez Solar, López González y Cueto Espinar, 1998).

Sobre el cumplimiento de la ley de Lotka, una vez determinadas la pendiente de la distribución de autores (-1.79) y la constante (0.5271), y obtenidos el valor crítico (0.056), tomando como referencia el nivel de significación $=0.01$, y la diferencia máxima (0.047), podemos confirmar que nuestra distribución de autores se ajusta bien a una distribución de tipo Lotka.

Dentro del conjunto de autores grandes productores conviene resaltar la existencia del mencionado grupo de 12 autores superproductores ( $\geq 40$ publicaciones) que, representando apenas el $1.41 \%$ de la autoría, aglutina hasta el $37.20 \%$ de la producción (813 documentos) (Tabla 2). Asimismo, es de interés referirnos a su filiación institucional: resulta significativo que únicamente 4 de los 12 autores estén asociados a instituciones académicas (Antonio Bel- 
trán Martínez a la Universidad de Zaragoza, Mauro Severo Hernández Pérez a la Universidad de Alicante, Martí Mas Cornellá a la UNED y Eduardo Ripoll Perelló, en distintas etapas, a las universidades de Barcelona, Oviedo, Bellaterra y a la Universidad Nacional de Educación a Distancia de Madrid) y que un quinto autor, Vicente Baldellou, se vincule a un organismo cultural dependiente de la administración, en este caso como director del Museo Provincial de Huesca. De los otros 7 autores, la mayor parte son profesores de enseñanza secundaria, salvo Ramón Viñas Vallverdú y Alexandre Grimal Navarro, ajenos por tanto a los círculos universitarios y a los organismos de tipo cultural dependientes de la administración, ya sea central o autonómica. En el caso de Ramón Viñas Vallverdú, ha desarrollado la mayor parte de su producción sin estar adscrito a una institución oficial concreta y sólo desde 2005 lo ha hecho desde su pertenencia al Instituto Catalán de Paleoecología Humana y Evolución Social, mientras que Alexandre Grimal es pintor artístico, sin adscripción a institución alguna.

Tabla 2. Grupo de autores superproductores (I. P., Índice de productividad)

\begin{tabular}{|c|c|c|c|c|c|c|}
\hline $\mathrm{N}^{0}$ & Autor & Public. & $\%$ & I.P. & $\begin{array}{c}\text { Periodo de } \\
\text { investigación }\end{array}$ & Filiación institucional \\
\hline 1 & $\begin{array}{l}\text { Beltrán Martínez, } \\
\text { Antonio }\end{array}$ & 179 & 8.18 & 2.25 & $1954-2006$ & Universidad de Zaragoza \\
\hline 2 & $\begin{array}{l}\text { Mateo Saura, } \\
\text { Miguel Ángel }\end{array}$ & 93 & 4.25 & 1.97 & $1991-2010$ & Docente en Enseñanza Secundaria \\
\hline 3 & Alonso Tejada, Ana & 92 & 4.20 & 1.96 & $1977-2010$ & Autora sin adscripción institucional \\
\hline 4 & \begin{tabular}{|l|} 
Viñas Vallverdú, \\
Ramón \\
\end{tabular} & 65 & 2.97 & 1.81 & $1971-2010$ & \begin{tabular}{|l|l|} 
Instituto Catalán de Paleoecología Hu- \\
mana y Evolución Social (2005-2015)
\end{tabular} \\
\hline 5 & $\begin{array}{l}\text { Grimal Navarro, } \\
\text { Alejandro } \\
\end{array}$ & 64 & 2.92 & 1.80 & $1985-2010$ & Pintor artístico \\
\hline 6 & $\begin{array}{l}\text { Baldellou Martínez, } \\
\text { Vicente }\end{array}$ & 60 & 2.74 & 1.77 & $1979-2010$ & $\begin{array}{l}\text { Director del Museo Provincial de } \\
\text { Huesca }\end{array}$ \\
\hline 7 & \begin{tabular}{|l} 
Hernández Pérez, \\
Mauro Severo \\
\end{tabular} & 48 & 2.19 & 1.68 & $1982-2009$ & Universidad de Alicante \\
\hline 8 & $\begin{array}{l}\text { Mas Cornellá, } \\
\text { Martí }\end{array}$ & 47 & 2.15 & 1.67 & 1985-2009 & $\begin{array}{l}\text { Universidad Nacional de Educación } \\
\text { a Distancia }\end{array}$ \\
\hline 9 & $\begin{array}{l}\text { Gómez-Barrera, } \\
\text { Juan Antonio }\end{array}$ & 44 & 2.01 & 1.64 & $1979-2010$ & Docente en Enseñanza Secundaria \\
\hline 10 & $\begin{array}{l}\text { Ripoll Perelló, } \\
\text { Eduardo }\end{array}$ & 41 & 1.87 & 1.61 & 1951-1997 & $\begin{array}{l}\text { Universidad de Barcelona (1953- } \\
\text { 1968); Universidad Autónoma de } \\
\text { Barcelona (1968); Universidad de } \\
\text { Oviedo (1969); Universidad de Bella- } \\
\text { terra (1970); Universidad Nacional } \\
\text { de Educación a Distancia (1981- } \\
\text { 1988); Emérito de la Universidad } \\
\text { Nacional de Educación a Distancia } \\
\text { (1988-2006) }\end{array}$ \\
\hline
\end{tabular}




\begin{tabular}{|l|l|c|c|c|c|l|}
\hline 11 & $\begin{array}{l}\text { López Payer, } \\
\text { Manuel Gabriel }\end{array}$ & 40 & 1.87 & 1.60 & $1973-2009$ & Docente en Enseñanza Secundaria \\
\hline 12 & $\begin{array}{l}\text { Soria Lerma, } \\
\text { Miguel }\end{array}$ & 40 & 1.82 & 1.60 & $1978-2009$ & Docente en Enseñanza Secundaria \\
\hline
\end{tabular}

En otro escalón de la producción, el protagonizado por aquellos autores que han publicado entre 10 y 39 trabajos, hay una mayor variedad en las instituciones de procedencia. Entre los 61 autores que conforman esta categoría, cuyos 835 trabajos constituyen el $38.19 \%$ de la producción, hay una mayor presencia de profesores universitarios o de autores que tenían algún tipo de vinculación con la universidad en el momento de edición de sus trabajos (27 autores, el $44.26 \%$ del grupo). Otros 23 investigadores (37.71\%) están asociados a organismos culturales, entre ellos son mayoría los directores de museos de titularidad municipal, y de la propia administración, a través de las Direcciones Generales de Cultura o entes públicos similares. Un último grupo lo forman 11 autores (18\%) que actúan al margen de los organismos universitarios y las institucionales oficiales, siendo muchos de ellos profesores de enseñanza primaria o secundaria.

\section{Autoría extranjera}

La participación de autores extranjeros en la investigación de la pintura rupestre postpaleolítica en España es, junto a la presencia de firmas nacionales en publicaciones extranjeras, uno de los indicios más fiables para evaluar su grado de internacionalización. Al respecto, son 72 los investigadores extranjeros que han publicado sobre el tema, lo que representa apenas el $8.51 \%$ de la autoría. Son autores o, en su caso coautores, de 193 trabajos, el $8.82 \%$ de la producción (Figura 1).

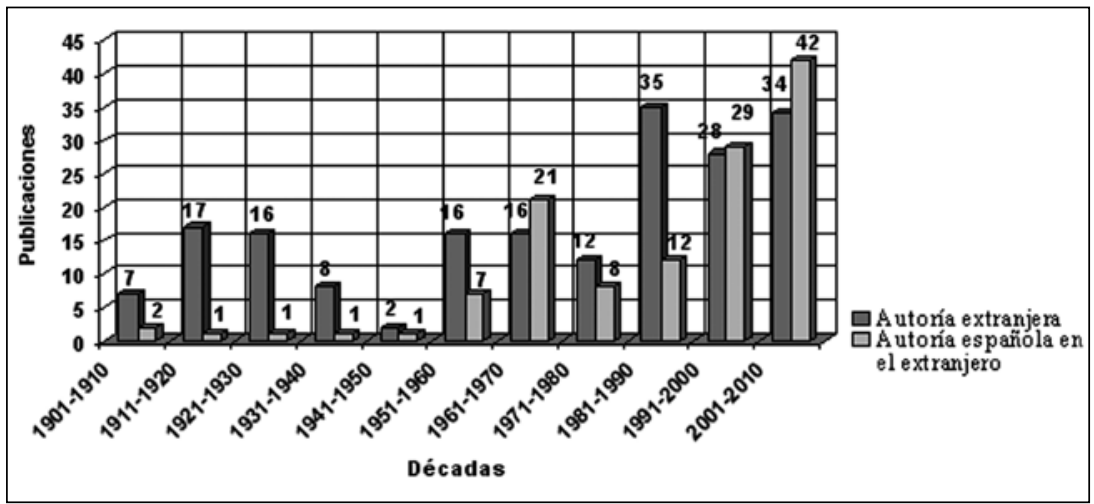

Figura 1. Distribución de la producción de los autores extranjeros, y de los autores españoles en el extranjero 
La labor de los investigadores extranjeros sí es destacada durante las primeras décadas de estudio, momento en que autores como Henri Breuil y Hugo Obermaier monopolizan la producción, pues entre los dos publican durante dicho lapso hasta 43 documentos, el $82.69 \%$ de todo lo editado hasta entonces. A ellos se unen puntuales aportaciones de otros investigadores como Paul Wernert, Herbert Kühn, Emil Cartailhac, Miles Burkitt, Henri Begoüen o George H. Luquet, la mayoría de las veces en coautoría con el propio Henri Breuil. Este hecho no resulta extraño puesto que la investigación del arte rupestre español durante estos primeros años va a estar en manos de instituciones extranjeras, como el Instituto de Paleontología Humana de París, o en su caso españolas, como la Comisión de Investigaciones Paleontológicas y Prehistóricas, a la que están vinculados algunos de los autores mencionados. Los pocos autores españoles del momento, procedentes de ámbitos tan dispares como las ciencias naturales o las bellas artes (consideremos que la prehistoria o la arqueología prácticamente no existen aún como disciplinas en España) suelen tener, salvo puntuales excepciones, un mero papel complementario.

En el periodo de 1931 a 1950 se reduce considerablemente la participación extranjera en la investigación de la pintura rupestre postpaleolítica española hasta el punto de ser prácticamente testimonial en la década de 1941-1950, en la que tan sólo registramos dos trabajos, consecuencia probablemente del aislamiento general que sufre el país. Ha sido a partir de los años ochenta cuando la presencia de autores extranjeros se incrementó de forma apreciable hasta alcanzar 97 publicaciones en estas tres últimas décadas, aunque siempre dentro de la parquedad que muestran las cifras globales dentro del total de la producción. No obstante, los datos de estos últimos 30 años podrían marcar un cambio de tendencia en lo que respecta a la participación de autores foráneos en la investigación del arte rupestre postpaleolítico español, si bien este extremo debería ser corroborado por un estudio posterior al nuestro. En todo caso, la reticencia de las revistas científicas españolas, salvo unas pocas excepciones, a aceptar originales en idiomas diferentes al español constituye un serio obstáculo para promover la llegada de trabajos realizados por investigadores extranjeros (Osca Lluch y Mateo Marquina, 2003).

\section{Autoría española en el extranjero}

Los 82 autores españoles que han publicado fuera de España (9.69 \%) son responsables de 125 trabajos, lo que supone el $60.97 \%$ de la producción publicada en el exterior y apenas el 5.71 \% de toda la producción (Figura 1). 
La presencia de autores españoles en publicaciones extranjeras es muy modesta durante los primeros 50 años de la investigación. Los pocos trabajos con que contamos son colaboraciones de autores españoles que firman en coautoría con aquellos autores extranjeros que dominan la investigación en estos momentos, sobre todo con Henri Breuil y Hugo Obermaier. A comienzos de los años cincuenta hallamos un mayor número de autores, que firman incluso en solitario, alcanzando un pico destacado para las cifras existentes hasta entonces para la década de 1961-1970, en la que se triplica el número de publicaciones del decenio anterior. Ha sido en los últimos 20 años de investigación cuando encontramos un número mayor de autores españoles en publicaciones extranjeras, aunque siempre en unos porcentajes bajos en relación al total de la autoría y de la producción. Sin embargo, al igual que planteábamos la posibilidad de un cambio de tendencia al comentar la presencia de autores extranjeros en la investigación de la pintura rupestre postpaleolítica peninsular, no estamos en condiciones de corroborar esta posibilidad al referirnos a la salida al exterior de los autores españoles. Sólo un estudio futuro, en el que se contemple una horquilla cronológica más amplia que estos últimos 20 años, ratificará lo que parece ser una línea de crecimiento o, en su caso, la modifique en sentido contrario.

\section{Análisis de la colaboración científica}

Los 2186 documentos computados arrojan un total de 3374 firmas, lo que proporciona un índice de colaboración de 1.54 firmas/trabajo. Los 1462 documentos firmados en solitario constituyen el grupo mayoritario, con el $66.88 \%$ del total de la producción, mientras que los otros 724 trabajos realizados en colaboración, que suponen el $33.11 \%$, presentan un reparto desigual. Hay un grupo destacado de 468 trabajos firmados por 2 autores, que representan el $21.40 \%$ de toda la producción y el $64.64 \%$ de los documentos realizados en colaboración. Con 3 firmas tenemos 147 documentos (6.7 \% de la producción y el $20.30 \%$ de la colaboración) y con 4 firmas hay 67 documentos, que suponen el $3.06 \%$ de toda la producción y el $9.25 \%$ de la colaboración. Los 42 documentos firmados por 5 o más autores constituyen una significativa minoría de apenas el $1.92 \%$ sobre el total de la producción y el 5.80 \% de los trabajos realizados en colaboración. De entre éstos, el número máximo de autores que firman conjuntamente un documento es de 11, que sólo encontramos en un trabajo (Tabla 3). 
Tabla 3. Distribución de las firmas/trabajo en el conjunto de la producción

\begin{tabular}{|c|c|c|c|c|}
\hline Número de firmas & $\begin{array}{c}\text { Número de } \\
\text { publicaciones }\end{array}$ & $\begin{array}{c}\text { \% sobre la } \\
\text { colaboración }\end{array}$ & $\begin{array}{c}\text { \% sobre el total de } \\
\text { publicaciones }\end{array}$ & $\begin{array}{c}\text { Número total de } \\
\text { firmas }\end{array}$ \\
\hline 11 & 1 & 0.14 & 0.04 & 11 \\
\hline 10 & 1 & 0.14 & 0.04 & 10 \\
\hline 9 & 3 & 0.41 & 0.14 & 27 \\
\hline 8 & 3 & 0.41 & 0.14 & 24 \\
\hline 7 & 9 & 1.24 & 0.41 & 63 \\
\hline 6 & 5 & 0.69 & 0.23 & 30 \\
\hline 5 & 20 & 2.76 & 0.92 & 100 \\
\hline 4 & 67 & 9.25 & 3.06 & 268 \\
\hline 3 & 147 & 20.30 & 6.72 & 441 \\
\hline 2 & 468 & 64.64 & 21.40 & 938 \\
\hline 1 & 1.462 & - & 66.88 & 1.462 \\
\hline Total colaboración & 724 & & 33.11 & - \\
\hline Totales & 2.186 & - & - & 3.374 \\
\hline
\end{tabular}

Vista la evolución de la colaboración científica en el periodo temporal analizado, vemos que ha alcanzado su máximo desarrollo en las tres últimas décadas de investigación, considerando que durante las tres primeras estuvo igualmente presente en una proporción muy modesta. Hasta 1970, los pocos trabajos firmados en colaboración tenían a lo sumo tres autores; de los 45 trabajos publicados en coautoría hasta ese año sólo cinco contaban con más de dos firmas. Ha sido a partir la década de los setenta cuando han crecido tanto el número de trabajos realizados en colaboración como el número de firmas por trabajo, aunque el grupo de documentos firmados por dos autores sigue siendo claramente mayoritario frente al resto, como lo ha sido a lo largo de todo el periodo de investigación. En la década 1991-2000 el porcentaje de la autoría múltiple asciende hasta el $40 \%$, mientras que en la década siguiente crece hasta el $41.45 \%$ (Tabla 4 ).

Tabla 4. Evolución temporal de la coautoría

\begin{tabular}{|c|c|c|c|c|c|c|c|c|c|c|c|}
\hline Década/firmas & 1 & 2 & 3 & 4 & 5 & 6 & 7 & 8 & 9 & 10 & 11 \\
\hline $1900-1910$ & 9 & 3 & 1 & - & - & - & - & - & - & - & - \\
\hline $1911-1920$ & 29 & 10 & 1 & - & - & - & - & - & - & - & - \\
\hline $1921-1930$ & 30 & 6 & 2 & - & - & - & - & - & - & - & - \\
\hline $1931-1940$ & 15 & 1 & 1 & - & - & - & - & - & - & - & - \\
\hline $1941-1950$ & 39 & - & - & - & - & - & - & - & - & - & - \\
\hline $1951-1960$ & 61 & 8 & - & - & - & - & - & - & - & - & - \\
\hline $1961-1970$ & 107 & 12 & - & - & - & - & - & - & - & - & - \\
\hline $1971-1980$ & 151 & 35 & 6 & 2 & 1 & - & 1 & - & - & - & - \\
\hline
\end{tabular}




\begin{tabular}{|c|c|c|c|c|c|c|c|c|c|c|c|}
\hline $1981-1990$ & 316 & 97 & 32 & 11 & 2 & 1 & 3 & 1 & - & - & - \\
\hline $1991-2000$ & 329 & 138 & 46 & 27 & 7 & 2 & - & - & 1 & - & - \\
\hline $2001-2010$ & 373 & 158 & 58 & 27 & 10 & 2 & 5 & 2 & 2 & 1 & 1 \\
\hline Sin fecha & 3 & - & - & - & - & - & - & - & - & - & - \\
\hline Total & 1.462 & 468 & 147 & 67 & 20 & 5 & 9 & 3 & 3 & 1 & 1 \\
\hline
\end{tabular}

El índice de colaboración de 33.11 \% obtenido en nuestro análisis es ligeramente superior al mostrado por el estudio bibliométrico efectuado sobre el arte rupestre levantino, en el que la colaboración suponía el 23.07 \% (Cruz Berrocal et al., 1999), estando también en consonancia con los mostrados por otros ámbitos de la arqueología. El análisis de las publicaciones sobre prehistoria editadas en la revista Trabajos de Prebistoria hasta el año 1993 indicaba un $28.52 \%$ de coautoría (Rodríguez Alcalde et al., 1993), mientras que el estudio de la Prehistoria por parte de la historiografía española y portuguesa durante las tres últimas décadas arrojaba un $32.30 \%$ de colaboración (García Marín et al., 1997). Más alto, en cambio, es el porcentaje de coautoría mostrado por el análisis de la investigación de los materiales cerámicos arqueológicos, en donde llega al 78.32 \% (García Heras, 1997). Sin embargo, en este caso hay que diferenciar entre aquellos trabajos realizados únicamente por arqueólogos, en los que la coautoría es del $59.01 \%$, de los firmados también por especialistas procedentes de las ciencias experimentales, en los que esta multidisciplinariedad eleva el porcentaje de coautoría hasta el $75.32 \%$.

Otras referencias a los índices de coautoría en el ámbito de la arqueología nos las ofrecen los estudios bibliométricos efectuados sobre varias revistas del área. En el Boletín de la Asociación de Amigos de la Arqueología el porcentaje de artículos realizados en colaboración apenas llega al 18.88 \% y de éstos, a su vez, el $74.07 \%$ están firmados únicamente por dos autores (Rovira Llorens, 1994). En la Revista d'Arqueologia de Ponent sólo el 34.82 \% de los artículos están firmados por dos o más autores, siendo también mayoritario, entre estos últimos, el grupo de dos firmantes, con el $49.57 \%$ (Armada, 2009). En el Archivo Español de Arqueología los 31 artículos publicados en coautoría en el periodo 1985-1996 apenas sumaban el 13.08 \% de lo editado en ese tiempo en la revista (García del Toro et al., 1999), mientras que los artículos firmados en coautoría hasta 1995 en Cota Zero suponían el 25.21 \% de los trabajos publicados (Cruells, 1995).

El bajo índice de la colaboración en las publicaciones sobre arqueología y prehistoria (Rodríguez Alcalde et al., 1996) está en consonancia con los bajos porcentajes que la coautoría suele presentar en el área de las ciencias sociales y, sobre todo, de las humanidades (Bordons y Gómez, 1997; Cronin, Shaw y 
La Barre, 2003), en todo caso inferiores a los índices de colaboración registrados en el ámbito de las ciencias experimentales y de la salud (Over, 1982). Al respecto, sirvan de ejemplo sendos trabajos realizados sobre la colaboración en las publicaciones de la Universidad de Extremadura, que confirmaron un porcentaje de coautoría en el ámbito científico-técnico del $89 \%$ frente al $46 \%$ de la colaboración en las áreas de ciencias sociales y humanidades ${ }^{2}$ (Pulgarín et al., 2003 y 2004). Datos similares obtuvieron Alonso Arroyo, Pulgarín Guerrero y Gil Leiva (2005) sobre la colaboración en la Universidad Politécnica de Valencia, en donde hallaron que la colaboración científica para los artículos de revista alcanzó el $86.29 \%$.

Este pobre porcentaje de colaboración reflejado por nuestro estudio parece indicar que la investigación de la pintura rupestre postpaleolítica permanece al margen de la tendencia general dentro de la ciencia, estando afectada, por el contrario, por fenómenos de localismo e individualidad que han estado presentes en ella desde sus comienzos.

Un panorama muy próximo es el que presenta el índice de colaboración que, entendido como el número de firmas por trabajo (Lawani, 1986), en nuestro análisis es de 1.54. Si en humanidades y ciencias sociales el número de autores por trabajo es de 1-2 frente a los 2.5-3.5 de las ciencias experimentales y tecnológicas (Bordons y Gómez, 1997; Sancho, 1990), nuestro índice de colaboración está por debajo de los 2.6 de la investigación sobre los materiales cerámicos arqueológicos (García Heras, 1997), pero cercano al 1.74 de los trabajos sobre prehistoria publicados en la revista Trabajos de Prebistoria hasta 1993 (Rodríguez Alcalde et al. 1993).

Es un hecho objetivo que la producción científica actual es, en general y con mayor frecuencia, producto de equipos de investigación, y que esta colaboración se relaciona positivamente con la productividad, de tal forma que los autores más productivos son los que más colaboran (Agulló Martínez y Aleixandre Benavent, 1999; Miguel Dasit, 2003; Valenciano et al., 2010). Sin embargo, a tenor de los datos que podemos manejar, deberemos convenir que la investigación de la pintura rupestre postpaleolítica española constituye una excepción a este postulado. Paradigmática sobre el particular es la producción científica generada por los 12 autores superproductores $(\geq 40$ publicaciones), que representa el $37.28 \%$ de toda la producción y que sirve para refrendar la escasa presencia que tiene la colaboración en nuestro ámbito de análisis. De los 813 trabajos publicados por estos autores, 384 han sido

2 No obstante, como los propios autores de los estudios reseñan, el hecho de que las fuentes de datos fueran distintas en cada caso, internacionales para el área científico-técnica y nacionales para el área de las ciencias sociales, también pudo repercutir de algún modo en los resultados finales. 
firmados en coautoría, lo que supone el $47.23 \%$ de su producción. Pero el índice de firmas/trabajo (IFT) es muy bajo, apenas el 1.70, lo que se explica porque la mayor parte de esos documentos firmados en coautoría, hasta el $69.01 \%$, cuenta únicamente con dos firmas (265). Aunque hay cuatro autores superproductores que firman en un porcentaje muy alto su producción en colaboración, otros ocho siguen teniendo un IFT por debajo de 2, al predominar, por un lado, los trabajos firmados en solitario sobre los realizados en coautoría, y por otro, porque estos últimos cuentan con un número de firmas muy bajo, prevaleciendo de forma destacada los trabajos que tienen únicamente dos firmas.

Muy revelador es el caso particular de los textos publicados por estos autores superproductores. El artículo es el tipo de documento mayoritario con mucha diferencia sobre el segundo formato de edición, con el $54.01 \%$ frente al $20.54 \%$ de las comunicaciones a congresos, y aunque ambos tipos de documentos suelen ser formatos idóneos para la edición en coautoría, en nuestro análisis constatamos la preeminencia del trabajo individual. El número de artículos firmados por estos 12 autores es de 439 y el número de firmas total es de 714, lo que arroja un IFT de 1.6 firmas/artículo. Muy significativo es el dato de que de los 439 artículos, hasta 241 cuenta con una sola firma (54.89\%), mientras que con tres o más firmas sólo hay 62 trabajos (14.12 \%) (Tabla 5).

Tabla 5. Distribución de firmas/trabajo en los artículos de los autores superproductores ( $\geq 40$ documentos)

\begin{tabular}{|c|c|c|c|c|c|c|c|c|}
\hline \multirow[t]{2}{*}{ Autor } & \multirow[t]{2}{*}{$\mathrm{N}^{0}$ de artículos } & \multirow[t]{2}{*}{$\mathrm{N}^{0}$ de firmas } & \multirow[t]{2}{*}{ IFT } & \multicolumn{5}{|c|}{$\mathrm{N}^{0}$ de firmas/trabajo } \\
\hline & & & & 1 & 2 & 3 & 4 & 5 \\
\hline $\begin{array}{l}\text { Beltrán Martínez, } \\
\text { Antonio }\end{array}$ & 103 & 115 & 1.11 & 92 & 10 & 1 & - & - \\
\hline $\begin{array}{l}\text { Mateo Saura, Miguel } \\
\text { Ángel }\end{array}$ & 57 & 82 & 1.43 & 38 & 13 & 6 & - & - \\
\hline $\begin{array}{l}\text { Baldellou Martínez, } \\
\text { Vicente }\end{array}$ & 44 & 79 & 1.79 & 29 & 2 & 6 & 7 & - \\
\hline \begin{tabular}{|l} 
Viñas Vallverdú, \\
Ramón
\end{tabular} & 42 & 89 & 2.11 & 10 & 19 & 11 & 2 & - \\
\hline Alonso Tejada, Ana & 37 & 72 & 1.94 & 7 & 25 & 5 & - & - \\
\hline $\begin{array}{l}\text { Gómez Barrera, Juan } \\
\text { Antonio }\end{array}$ & 30 & 44 & 1.46 & 22 & 5 & 1 & 1 & 1 \\
\hline $\begin{array}{l}\text { Grimal Navarro, } \\
\text { Alexandre } \\
\end{array}$ & 23 & 42 & 1.82 & 4 & 19 & - & - & - \\
\hline $\begin{array}{l}\text { López Payer, Manuel } \\
\text { Gabriel }\end{array}$ & 23 & 52 & 2.26 & - & 17 & 6 & - & - \\
\hline Soria Lerma, Miguel & 23 & 52 & 2.26 & - & 17 & 6 & - & - \\
\hline $\begin{array}{l}\text { Ripoll Perelló, } \\
\text { Eduardo }\end{array}$ & 22 & 23 & 1.04 & 21 & 1 & - & - & - \\
\hline
\end{tabular}




\begin{tabular}{|l|c|c|c|c|c|c|c|c|}
\hline Mas Cornellá, Martí & 19 & 31 & 1.63 & 13 & 3 & 1 & 1 & 1 \\
\hline $\begin{array}{l}\text { Hernández Pérez, } \\
\text { Mauro Severo }\end{array}$ & 16 & 33 & 2.06 & 5 & 5 & 6 & - & - \\
\hline Totales & 439 & 714 & - & 241 & 136 & 49 & 11 & 2 \\
\hline
\end{tabular}

Si ampliamos el ámbito de análisis a la producción de los 73 autores que firman 10 o más documentos, el panorama no cambia sustancialmente, ofreciendo además algún detalle expresivo. Los trabajos firmados en solitario, que son 921 y suponen el $49.9 \%$ del global de su producción, siguen teniendo un peso muy importante. De hecho, de estos 73 autores únicamente 7 , apenas el $9.58 \%$, ha firmado toda su producción en coautoría, mientras que otros 18 autores, el $24.65 \%$, cuentan con menos de 5 documentos firmados en solitario. Otros 2 autores han realizado toda su producción en solitario, mientras que 7 más tienen una producción en coautoría prácticamente testimonial. Al mismo tiempo, de entre los 938 trabajos firmados en colaboración por estos 73 autores, el grupo más numeroso es el de los trabajos que cuentan con dos firmas, con 525 (55.97 \%). Conforme aumenta el número de firmas disminuye significativamente el número de trabajos publicados (Tabla 6). El IFT de este grupo de autores es de 1.92, ligeramente superior al 1.54 del global la producción.

Tabla 6. Distribución de firmas/trabajo entre los autores con 10 o más documentos.

\begin{tabular}{|c|c|c|}
\hline $\begin{array}{c}\text { Número de } \\
\text { firmas }\end{array}$ & $\begin{array}{c}\text { Número de } \\
\text { documentos }\end{array}$ & $\begin{array}{c}\% \text { sobre } \\
\text { coautoría }\end{array}$ \\
\hline 2 & 525 & 55.97 \\
\hline 3 & 239 & 25.47 \\
\hline 4 & 104 & 11.08 \\
\hline 5 & 25 & 2.66 \\
\hline 6 & 13 & 1.38 \\
\hline 7 & 10 & 1.06 \\
\hline 8 & 9 & 0.95 \\
\hline 9 & 12 & 1.27 \\
\hline 10 & 0 & 0 \\
\hline 11 & 1 & 0.10 \\
\hline Total & 938 & 100 \\
\hline
\end{tabular}

Estos datos parecen contradecir la relación positiva que en otros ámbitos de la ciencia tienen colaboración científica y productividad (Arora y Pawan, 1995; Agulló Martínez y Aleixandre Benavent, 1999; Beaver y Rosen, 1978, 1979; Pao, 1982). Price (1963), quien vaticinaba que a finales del siglo XX toda la ciencia sería producto de equipos de investigación, acuñó el concepto 
de Gran Ciencia (Big Science), en contraposición al de Little Science, para definir a aquella que es producto de la colaboración frente a otra de carácter más "artesanal", en terminología de Agulló Martínez y Aleixandre Benavent (1999), y caracterizada por la individualidad. Si consideramos los datos derivados de nuestro análisis podemos pensar que el estudio de la pintura rupestre postpaleolítica de España todavía no ha alcanzado ese grado de madurez y de profesionalización que sí se concede a otras disciplinas científicas en virtud de este indicador.

La presencia de firmas múltiples se ha relacionado positivamente con el apoyo económico, de forma que la escasez de este tipo de ayuda para la investigación hace que la ciencia se tenga que apoyar en la iniciativa personal (Agulló Martínez y Aleixandre Benavent, 1999). Si bien es cierto que en nuestro ámbito de análisis la colaboración ha alcanzado en las dos últimas décadas de la investigación un desarrollo desconocido hasta entonces, con unos porcentajes destacados del $40 \%$ en el periodo 1991-2000 y del $41.45 \%$ entre 2001-2010, también lo es que al día de hoy no estamos en condiciones de poder afirmar que tales cifras marquen una línea consolidada hacia el aumento del índice de colaboración que, por el contrario, está lejos de mostrar un crecimiento continuado.

Sólo en los años 1999 y 2010 los trabajos realizados en colaboración superan, con unas diferencias nada apreciables, a los realizados en solitario, 50/49 y 18/16 respectivamente, mientras que en el año 1997 se igualan a 22. En el resto del periodo referido los trabajos firmados en solitario son significativamente mayoritarios y el volumen anual de aquellos realizados en colaboración presentan unas marcadas fluctuaciones de un año a otro. Entre 1991 y 2000, el porcentaje de la colaboración científica oscila entre el $25 \%$ de 1992 y el $45.45 \%$ de 1994, mientras que en la década siguiente, la colaboración aumenta ligeramente, situándose entre el $38.93 \%$ de 2006 y el $47.05 \%$ de 2003, aunque debemos reseñar como excepcional dentro de esta década el año 2009, en el que la colaboración apenas llegó al 25 \% de lo publicado. Son estos dientes de sierra en los porcentajes de coautoría los que impiden hablar de un crecimiento consolidado de la colaboración científica.

\section{Colaboración internacional}

Si la firma de investigadores foráneos podía ser un indicio más que fiable sobre el grado de internacionalización de la investigación y del interés que la historiografía extranjera podía mostrar hacia el tema, los datos obtenidos en lo que respecta a la colaboración con autores foráneos parecen corroborar lo que apuntábamos sobre que no ha sido éste uno de los campos de investiga- 
ción de la prehistoria peninsular que mayor interés haya despertado entre los investigadores extranjeros. De los 193 trabajos en los que hay participación de investigadores foráneos, 71 han sido firmados en colaboración (36.78 \%), aunque en el contexto general de la coautoría, estos trabajos apenas suponen el $9.80 \%$ del total de la producción realizada en colaboración.

Las 71 publicaciones firmadas en coautoría proporcionan un total de 347 firmas, lo que arroja para la colaboración internacional un IFT de 1.79, índice que es ligeramente superior al 1.54 mostrado por la colaboración en el total de la producción. En cuanto al número de firmas, 36 documentos han sido firmados por 2 autores $(50.70 \%)$ mientras que en el polo opuesto contamos con un único trabajo firmado por 11 autores (1.40\%).

La distribución temporal de los 71 trabajos con coautoría extranjera revela una presencia destacada de la misma durante las tres primeras décadas de la investigación, en donde supone el 60.86 \% , con 14 de 23 documentos. La causa la encontramos en el ya mencionado protagonismo que por entonces tienen en la investigación del arte rupestre peninsular tanto investigadores como organismos extranjeros, mientras que la autoría española, minoritaria, adquiere un carácter prácticamente secundario respecto de aquélla. De hecho, uno de los autores extranjeros más productor, y a la vez más colaborador, es Henri Breuil, que firma 10 de sus 30 trabajos en coautoría tanto con autores extranjeros, caso de Hugo Obermaier, Emil Cartailhac o Mile Burkitt, como con autores españoles, como Juan Cabré, Federico de Motos, Pascual Serrano o Juan Bautista Porcar. Entre 1931 y 1950 hay un acusado descenso de la coautoría internacional paralelo al de la producción general (1 de 2 documentos), consecuencia de la Guerra Civil y el posterior aislamiento internacional.

Entre 1951 y 1970 se observa una ligera recuperación de la colaboración internacional, al alcanzar el 35 \% de la coautoría (7 documentos de 20) para volver prácticamente a desaparecer en la década de 1971 a 1980, en la que se sitúa en un pobre $4.44 \%$ (2 trabajos de 45 ). Desde el inicio de los años ochenta, la coautoría con investigadores extranjeros ha iniciado un periodo de modesto crecimiento, aunque las cifras apenas llegan al $8.63 \%$ (47 de 544 documentos) (Figura 2, pág. s.).

De los 71 documentos que cuentan con coautoría extranjera, 45 están firmados por autores españoles y extranjeros (63.38\%), mientras que 26 tienen como firmantes sólo autores extranjeros (36.61\%). Los índices máximos de colaboración entre investigadores españoles y extranjeros se han alcanzado en las tres últimas décadas de la investigación, en las que se ha desarrollado el $75.50 \%$ de la misma (Tabla 7, pág. s.). 


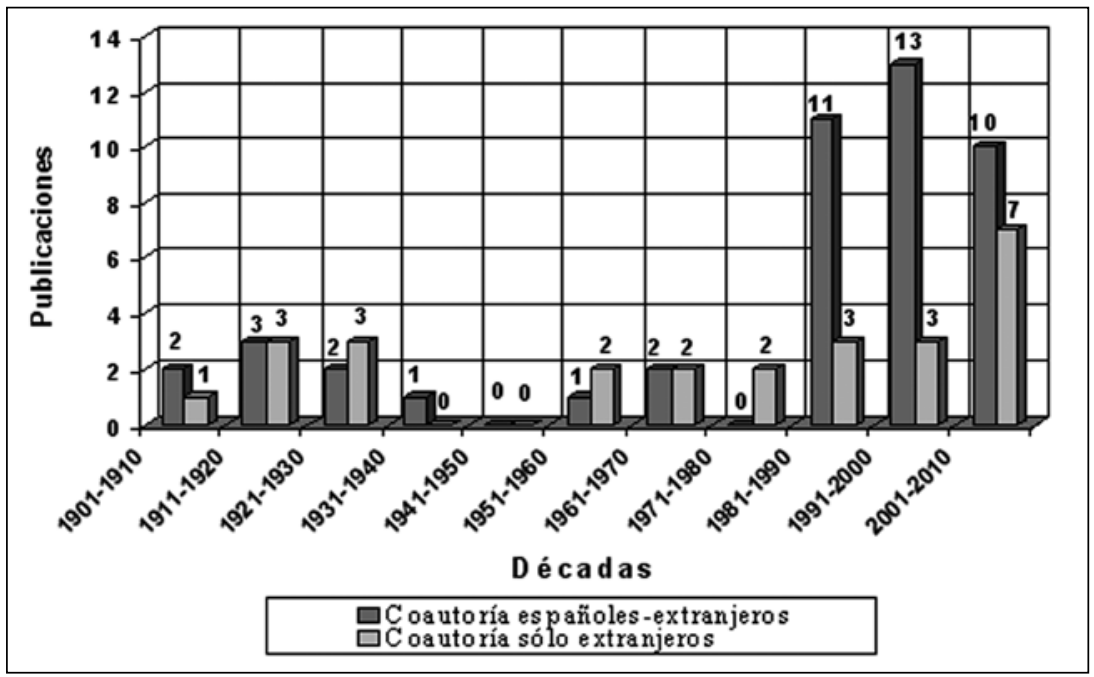

Figura 2. Evolución de la colaboración entre autores españoles y extranjeros

Tabla 7. Distribución de la colaboración internacional

\begin{tabular}{|l|c|c|c|c|c|c|c|c|c|c|c|c|c|}
\hline \multirow{2}{*}{$\begin{array}{c}\text { Tipo de } \\
\text { co-autoría }\end{array}$} & Número de & \multicolumn{8}{|c|}{ Número de firmas/trabajo } & Total & \multirow{2}{*}{ IFT } \\
\cline { 3 - 17 } & trabajos & 2 & 3 & 4 & 5 & 6 & 7 & 8 & 9 & 10 & 11 & firmas & \\
\hline Españoles - Extranjeros & 45 & 12 & 12 & 12 & 2 & 2 & 3 & 0 & 1 & 0 & 1 & 171 & 3,80 \\
\hline Todos extranjeros & 26 & 24 & 2 & 0 & 0 & 0 & 0 & 0 & 0 & 0 & 0 & 54 & 2,07 \\
\hline
\end{tabular}

\section{Grupos de colaboración}

El análisis de redes lo realizamos desde la observación de la red de coautorías ya que, aunque se admiten ciertas limitaciones del método, también se considera que es un procedimiento útil para definir la existencia de grupos de investigación (Molina, Muñoz y Doménech, 2002; Russell, Madera Jaramillo y Ainsworth, 2009). Éstos podrían ser entendidos como redes de comunicación informal con alguna forma de organización social (Pulgarín, Lagar y Escalona, 2010), más o menos claros en su formación y estables en la colaboración científica (Carpintero y Peiró, 1981). Si consideramos, además, que un análisis de la colaboración a partir de la coautoría tiene la ventaja de no precisar un conocimiento previo del grupo a estudiar en cuestiones como la filiación institucional de los autores (Zulueta, Cabrero y Bordons, 1999), el uso de la misma se nos presenta como una herramienta útil para hacer una primera aproximación a la definición de eventuales grupos de colaboración (Pulgarín, Lagar y Escalona, 2010). 
De acuerdo con los criterios expuestos en el apartado de Material y método, varios han sido los grupos de colaboración definidos, la mayor parte de los cuales tienen como investigador principal a alguno de los autores superproductores ( $\geq 40$ publicaciones) (Tabla 8 ). De entre éstos, los tres autores más colaboradores son Ana Alonso Tejada, Miguel Soria Lerma y Ramón Viñas Vallverdú, cuya producción realizada en coautoría supera ampliamente a la firmada en solitario por cada uno de ellos.

Tabla 8. Grupos de investigación (D., Densidad; I. P., Índice de productividad; IFT, Índice de firmas/trabajo)

\begin{tabular}{|c|c|c|c|c|c|c|c|c|c|c|c|c|c|c|c|}
\hline \multirow{2}{*}{$\begin{array}{c}\text { Investigador } \\
\text { principal }\end{array}$} & \multirow{2}{*}{$\begin{array}{c}\text { Núm. de } \\
\text { miembros }\end{array}$} & \multicolumn{2}{|c|}{ Publicaciones } & \multirow[b]{2}{*}{ D } & \multirow[b]{2}{*}{ I. P. } & \multirow[b]{2}{*}{ IFT } & \multicolumn{9}{|c|}{ Núm. de firmas/trabajo } \\
\hline & & $\begin{array}{c}\text { En } \\
\text { solitario }\end{array}$ & \begin{tabular}{|c|} 
En \\
coautoría
\end{tabular} & & & & 1 & 2 & 3 & 4 & 5 & 6 & 7 & 8 & $\leq 9$ \\
\hline $\begin{array}{l}\text { Viñas Vallver- } \\
\text { dú, Ramón }\end{array}$ & 40 & 21 & 44 & 0.10 & 1.62 & 2.20 & 21 & 23 & 14 & 5 & & 1 & & 1 & \\
\hline $\begin{array}{l}\text { Martínez } \\
\text { Valle, Rafael }\end{array}$ & 36 & 9 & 29 & 0.15 & 1.05 & 3.02 & 9 & 11 & 7 & 5 & 2 & & 1 & 1 & 2 \\
\hline $\begin{array}{l}\text { Mas Cornellá, } \\
\text { Martí }\end{array}$ & 32 & 36 & 11 & 0.20 & 1.47 & 2.56 & 36 & 3 & 3 & 2 & 1 & & 1 & & 1 \\
\hline $\begin{array}{l}\text { Alonso } \\
\text { Tejada, Ana }\end{array}$ & 20 & 19 & 73 & 0.17 & 4.60 & 1.97 & 19 & 61 & 9 & 2 & & 1 & & & \\
\hline $\begin{array}{l}\text { Beltrán } \\
\text { Martínez, } \\
\text { Antonio } \\
\end{array}$ & 18 & 153 & 26 & 0.26 & 9.94 & 0.35 & 153 & 22 & 2 & & 1 & & & 1 & \\
\hline $\begin{array}{l}\text { Baldellou } \\
\text { Martínez, } \\
\text { Vicente }\end{array}$ & 16 & 40 & 20 & 0.32 & 3.75 & 1.83 & 40 & 3 & 7 & 9 & & & 1 & & \\
\hline $\begin{array}{l}\text { Gómez-Ba- } \\
\text { rrera, Juan } \\
\text { Antonio }\end{array}$ & 14 & 35 & 9 & 0.30 & 3.14 & 1.38 & 35 & 5 & 1 & 2 & 1 & & & & \\
\hline $\begin{array}{l}\text { Collado } \\
\text { Giraldo, } \\
\text { Hipólito }\end{array}$ & 11 & 22 & 3 & 0.40 & 2.18 & 1.45 & 22 & 2 & 1 & & & & & & \\
\hline $\begin{array}{l}\text { Hernández } \\
\text { Pérez, Mauro } \\
\text { Severo }\end{array}$ & 11 & 25 & 23 & 0.30 & 4.36 & 1.79 & 25 & 10 & 12 & & 1 & & & & \\
\hline Breuil, Henri & 10 & 20 & 10 & 0.46 & 3 & 1.43 & 20 & 7 & 3 & & & & & & \\
\hline $\begin{array}{l}\text { Mateo Sau- } \\
\text { ra, Miguel } \\
\text { Ángel } \\
\end{array}$ & 9 & 53 & 40 & 0.36 & 10.33 & 1.55 & 53 & 28 & 12 & & & & & & \\
\hline $\begin{array}{l}\text { Soria Lerma, } \\
\text { Miguel }\end{array}$ & 9 & 3 & 37 & 0.44 & 4.77 & 2.16 & 3 & 26 & 10 & 1 & & & & & \\
\hline
\end{tabular}

La producción de la mayor parte de los 12 grupos de investigación determinados se inicia a partir de los años setenta. En concreto, los tres grupos dirigidos por Ana Alonso Tejada, Vicente Baldellou Martínez y Ramón Viñas Vallverdú, respectivamente, comienzan sus colaboraciones ya a finales de 
esa década; otros cuatro lo hacen en la década de los ochenta, dirigidos por Juan Antonio Gómez-Barrera, Mauro Severo Hernández Pérez, Martí Mas Cornellá y Miguel Soria Lerma, y tres más inician su producción en los años noventa, los de Hipólito Collado Giraldo, Rafael Martínez Valle y Miguel Ángel Mateo Saura. Durante los primeros 20 años de investigación tan sólo podríamos reseñar la existencia de un grupo de investigación, articulado en torno a la figura de Henri Breuil, mientras que a partir de los años cincuenta será Antonio Beltrán Martínez quien encabece otro de estos equipos de trabajo. No obstante, tanto el grupo de Henri Breuil como el de Antonio Beltrán Martínez muestran una particular colaboración en la que la mayor parte de los integrantes de sus respectivos grupos son colaboradores ocasionales, ya que únicamente firman un documento con el investigador principal. En todo caso debemos señalar que es ésta una característica muy extendida entre la mayor parte de los grupos establecidos, si bien de forma menos acusada. La producción generada por estos grupos de investigación es de 761 documentos, lo que supone el $34.81 \%$ del global de la producción.

Del análisis de los grupos de investigación definidos y de la producción científica generada por ellos, observamos que no hay una correlación positiva entre el número de miembros del grupo y el número de trabajos publicados por ellos. Los grupos más numerosos no suelen ser los que más publican, de tal forma que si bien el grupo más grande, de 40 investigadores, publica 65 trabajos, también nos encontramos con otros tres grupos de investigación que, integrados por menos de 20 investigadores, superan el número de publicaciones e incluso llegan a duplicarlas. El hecho de que no exista esa correlación positiva entre el número de miembros del grupo y el número de publicaciones está fuertemente mediatizado por el destacado peso específico de la producción firmada en solitario por los investigadores principales de cada grupo (Figura 3, pág. s.).

En cuanto a la cohesión de los grupos de investigación, la baja densidad reflejada en todos ellos indica que la colaboración entre autores disminuye conforme aumenta el tamaño de los grupos, de tal forma que los datos manifiestan que la densidad es mayor cuando los grupos están formados por pocos investigadores. En nuestro caso, los grupos integrados por nueve miembros son los que presentan un mayor grado de cohesión. 


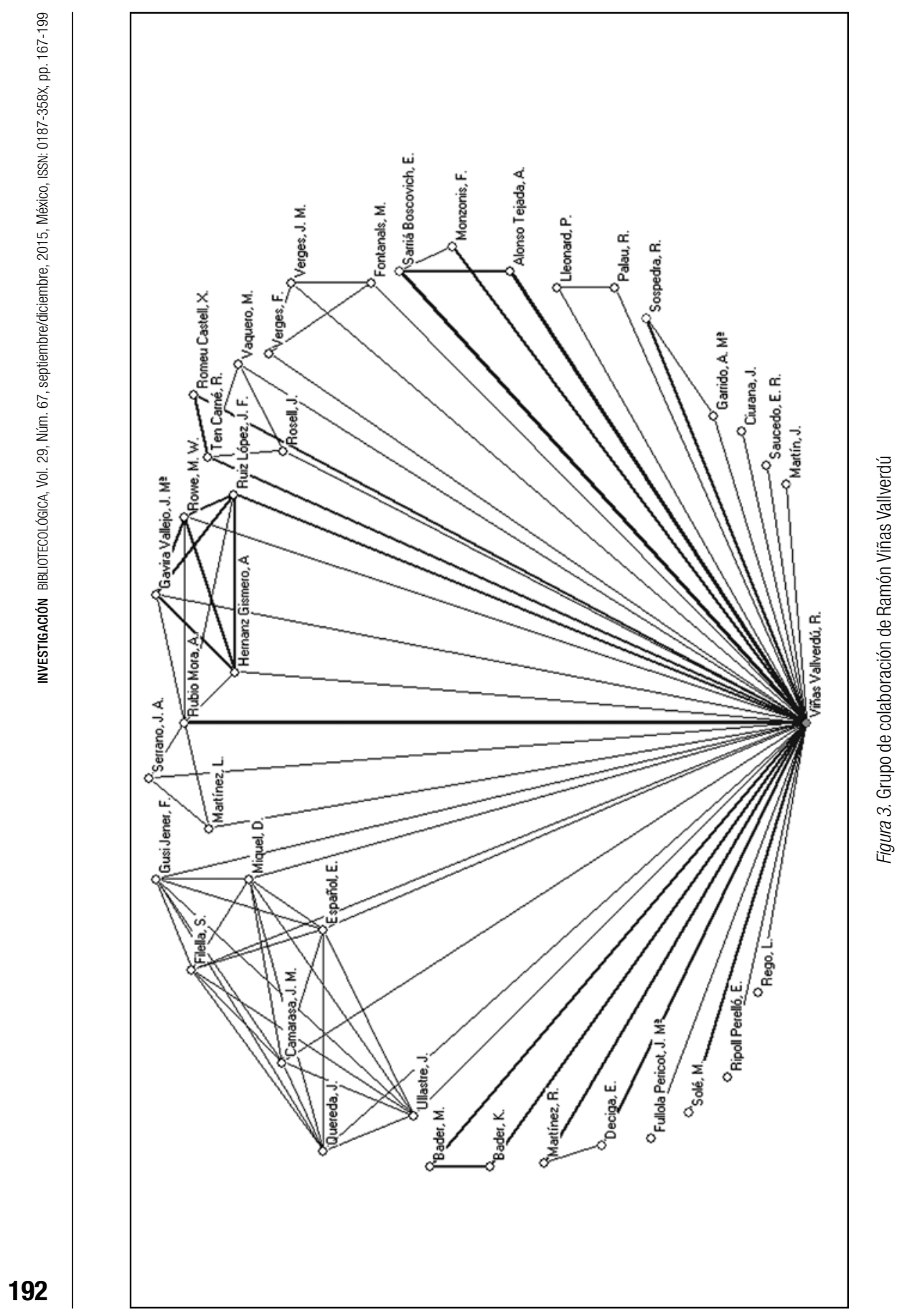




\section{Conclusiones}

Si el análisis de la producción científica sobre la pintura rupestre postpaleolítica española durante el periodo 1907-2010 evidencia, en su conjunto, algunos de los rasgos que han caracterizado la propia producción, entre ellos su acentuado localismo y la escasa proyección internacional (Mateo Saura, 2013), el estudio de la autoría refleja también algunas particularidades susceptibles de cambio si se pretende que la disciplina alcance los parámetros propios de una ciencia moderna.

Una primera cuestión debe ser la superación del individualismo que tradicionalmente ha caracterizado la propia investigación a favor de la colaboración científica, a partir de la formación de grupos interdisciplinares de trabajo. Como se señaló en un trabajo precedente al nuestro (Cruz Berrocal et al., 1999), este personalismo ha sido seña de identidad en el estudio del arte prehistórico en general y del levantino en particular desde los inicios de la propia investigación. Es cierto que, como hemos reseñado, la colaboración científica desde la coautoría se ha visto incrementada en la segunda mitad del periodo de estudio, en la que incluso sus porcentajes aumentan puntualmente hasta alcanzar casi un $42 \%$ como pasa en la última década de trabajo, pero también lo es que se trata de una colaboración muy particular si consideramos que un $64.64 \%$ de toda la producción realizada en colaboración únicamente cuenta con dos firmas y que sólo un $5.80 \%$ de lo producido en coautoría tiene cinco o más firmantes.

Se han señalado algunas de las ventajas que ofrece un trabajo en equipo, entre ellas las económicas al repartir costos, favorecer el acceso a recursos que de otra forma podrían ser inalcanzables o la necesidad de formalizar redes que proporcionen visibilidad. Pero, por encima de todas ellas, creemos que sin un trabajo interdisciplinar es difícil desarrollar actualmente una investigación exhaustiva y de calidad del arte rupestre prehistórico. Durante mucho tiempo, en su estudio ha bastado con un análisis descriptivo, basado en lo iconográfico, tarea que generalmente asumía una única persona, casi siempre un especialista en Prehistoria. Sin embargo, la nueva concepción del arte prehistórico más allá de un simple hecho iconográfico y que recomienda la aplicación en su estudio de técnicas provenientes de otros ámbitos de la ciencia obliga a la formación de equipos de trabajo interdisciplinares que permitan abordar el examen de la pintura rupestre prehistórica en sus diversas facetas.

En estos últimos años se han editado unos pocos trabajos que se podrían encuadrar en esta nueva forma de investigación del arte prehistórico, pero la realidad nos dice que en las dos décadas de estudio más recientes, cuando la 
colaboración alcanza sus máximas cotas, el trabajo individual sigue estando próximo al $60 \%$ de la producción. En este sentido, es muy revelador que de la producción generada por los 12 autores superproductores, que con 813 documentos supone el $37.20 \%$ de la producción total, el 52.77 \% se firma en solitario (429 documentos). Así las cosas, los datos con que contamos no nos permiten afirmar que se trate de una línea de trabajo en vías de consolidación ya que la tendencia mayoritaria aún hoy en este campo de investigación sigue siendo el trabajo individual.

En íntima relación con el personalismo que ha caracterizado la investigación de la pintura rupestre prehistórica hemos visto cómo gran parte de ésta ha descansado, y aún hoy día lo hace, en el trabajo de investigadores que no están adscritos a instituciones académicas u organismos de la administración. Así, de entre el grupo de los 12 autores más productores ( $\geq 40$ publicaciones) tan sólo cinco están vinculados a un organismo oficial, cuatro de ellos a la universidad y el quinto a un museo. Si tenemos en cuenta que las instituciones son las encargadas de proporcionar los recursos materiales y económicos necesarios para la investigación, es fácil suponer que gran parte de la labor desarrollada por estos investigadores independientes o bien ha dependido de la obtención de ayudas externas, o bien se ha concretado en un trabajo más artesanal, obligado por la eventual disponibilidad de recursos. Esta situación, que sensu stricto podría acreditar una evidente falta de profesionalismo en este ámbito de estudio, en modo alguno debe entenderse como algo peyorativo hacia la labor honrada de estos investigadores, entre otras razones porque, a pesar de las limitaciones que su trabajo haya podido padecer, no cabe duda de que sin él la investigación de la pintura rupestre postpaleolítica española estaría muy lejos de mostrar la producción científica que hoy presenta. Pero sí debe servir como llamada de atención para que, en la medida de lo posible, los especialistas en la investigación del arte rupestre se incorporen a aquellas instituciones que tienen responsabilidad en la materia, o en su caso, que sean las propias instituciones las que habiliten los recursos necesarios para el desarrollo de un trabajo eficaz que, dirigido por estos especialistas, contemple la formación de esos equipos interdisciplinares a los que aludíamos, básicos para el desarrollo de una investigación moderna del arte rupestre.

\section{BiBLIOGRAFÍA}

Abad Pérez, I. (1987), La aportación de la Comunidad Valenciana a la ciencia médica (1980-1984), tesis de doctorado, Valencia, Facultad de Medicina, Universitat de València. 
Agulló Martínez, A. (1998), Estudio bibliométrico de las publicaciones médicas españolas analizadas en el Índice Médico Español (19891991), tesis de doctorado, Valencia, Departamento de Historia de la Ciencia y Docuentación, Universitat de València.

—_ y Aleixandre Benavent, R. (1999), "Evolución del índice de colaboración de los artículos médicos españoles en la presente centuria”, en Papeles Médicos, 8, 16-20.

Alonso Arroyo, A.; Pulgarín Guerrero, A. y Gil Leiva, I. (2005), "Estudio cienciométrico de la colaboración científica en la Universidad Politécnica de Valencia, España", en Información Research, 11 (1), paper 245. Disponible en http://InformationR.net/ir/11-1/pa per245.html [Fecha de consulta: 20 de febrero de 2011].

Álvarez-Solar, M.; López-González, M. L. y Cueto-Espinar, A. (1998), "Indicadores bibliométricos, análisis temático y metodológico de la investigación pública en España sobre epidemiología y salud pública”, en Medicina Clínica, 111 (14), 529-535.

Armada, X. L. (2009), "Indicadores bibliométricos, visibilidad y calidad de revistas científicas: en torno a Revista d'Arqueologia de Ponent", en Revista d'Arqueologia de Ponent, 19, 7-28.

Arora, J. y Pawan, U. (1995), "Collaborative research and authorship patterns in immunology: correlation between multiple authorship citednees", en Iaslic Bulletin, 40 (2), 73-83.

Batagelj, V. y Mrvar, A. (2007), Pajek software. Disponible en: http:// pajek.imfm.si/doku.php [Fecha de consulta: 24 de junio de 2014].

Beaver, D. de B. y Rosen, R. (1978), "Studies in scientific collaboration I. The professional origins of scientific co-authorship", en Scientometrics, 1 (1), 527-538.

— y Rosen, R. (1979), "Studies in scientific collaboration II. Professionalizaction and the natural history of modern scientific co-authorship", en Scientometrics, 1 (3), 231-245.

Bordons, M. y Gómez, I. (1997), "La actividad científica española a través de indicadores bibliométricos en el periodo 1990-1993)", en Revista General de Información y Documentación, 7 (2), 69-86.

— y Zulueta, Ma. A. (1999), "Evaluación de la actividad científica a través de los indicadores bibliométricos", en Revista Española de Cardiología, 52, 790-800.

; Cabrero, A. y Barrigón, S. (1995), "Identifying research teams with bibliometric tools”, en M. E. Koening y A. Brookstein (eds.), Proceedings of the Fifth Biennial Conference of the International Society for Scientometrics and Informetrics, Medford, Learnes Information, 83-92.

Carpintero, H. y Peiró, J. M. (1981), Psicología Contemporánea. Teoría y métodos cuantitativos para el estudio de su literatura científica, Valencia, Alfaplús.

Crane, D. (1972), Invisible colleges. Diffusion of Knowledge in scientific communities, Chicago, The Chicago University Press. 
Cronin, B.; Shaw, D. y La Barre, K. (2003), "A cast of thousands: coauthorship and subauthorship collaboration in the 20th century as manifested in the scholarly journal literature of psychology and philosophy", en Journal of the American Society for Information Science and Technology, 54 (9), 855-871.

Cruells, W. (1995), "Aproximació bibliomètrica i indexs de Cota Zero (1985-1995)”, en Cota Zero, 11, 100-122.

Cruz Berrocal, M.; Goytre Samaniego, J.; Leal Valladares, J. G. y López Domínguez, M. (1999), "Crítica al estudio del arte rupestre levantino desde una perspectiva bibliométrica”, en Trabajos de Prehistoria, 56 (1), 53-75.

García del Toro, M. A.; García Abolló, J. L.; Juárez Pérez, M. y López Guerao, M. A. (1999), "Estudio bibliométrico de la revista Archivo Español de Arqueología: foro nacional de investigación arqueológica”, en Actas del XXIV Congreso Nacional de Arqueología, 1997, Cartagena, 329-339.

García Heras, M. (1997), "Estudio bibliométrico de los trabajos de caracterización sobre materiales cerámicos arqueológicos en España: una valoración", en Revista d'Arqueologia de Ponent, 7, 129. 150.

García Marín, A.; Rodríguez Alcalde, A. L.; San Millán Bujanda, M. J.; Vicente Bobadilla, G. de y Martínez Navarrete, M. I. (1997), “ ¿Nos pasamos de la raya?: la frontera hispano-portuguesa a través de las publicaciones de Prehistoria y Protohistoria", en Trabajos de Prebistoria, 54 (1), 35-56.

— y Román Román, A. (1998), "Las publicaciones periódicas de Historia Antigua, Prehistoria y Arqueología: difusión internacional", en Trabajos de Prehistoria, 55 (1), 139-146.

González de Dios, J.; Moya, M. y Mateos, M. A. (1997), "Indicadores bibliométricos: características y limitaciones en el análisis de la actividad científica”, en Anales Españoles de Pediatría, 47, 235-244.

Hernanz Gismero, A. y Ruiz López, J. F. (2012), "Estudio espectroscópico $\mu$-Raman de pigmentos del Abrigo Riquelme”, en Las pinturas rupestres esquemáticas del Abrigo Riquelme. Jumilla, Murcia, Murcia, Dirección General de Bienes Culturales, 151-154. (Monografías del Centro de Estudios de Prehistoria y Arte Rupestre, 2.)

Lawani, S. M. (1986), "Some bibliometric correlatos of quality in scientific research", en Scientometrics, 9, 13-25.

López Piñero, J. M. y Terrada, M. L. (1992), "Los indicadores bibliométricos y la evaluación de la actividad médico-científica (III). Los indicadores de producción, circulación, dispersión, consumo de la información y repercusión”, en Medicina Clínica (Barcelona), 98 (4), 142-148.

Lotka, A. J. (1926), "The frecuency distribution of scientific productivity", en Journal Washington Academy Science, 16 (12), 317-323.

Maltrás Barba, B. (2003), Los indicadores bibliométricos. Fundamentos y aplicación al análisis de la ciencia, Gijón, Trea. 
Martínez Fernández, M. (1996), Análisis bibliométrico de la producción científica sobre radiodiagnóstico a través de la revista Radiología (1984-1993), tesis de doctorado, Murcia, Facultad de Medicina, Universidad de Murcia.

Mateo Saura, M. A. (1992), Arte naturalista en Murcia. Aspectos socioeconómicos y etnográficos, memoria de licenciatura, Murcia, Facultad de Letras, Universidad de Murcia.

(2001), "Arte levantino adversus pintura esquemática. Puntos de encuentro y divergencias entre dos horizontes culturales de la Prehistoria peninsular", en Quaderns de Prehistòria i Arqueología de Castelló, 22, 183-211.

(2009), Arte rupestre levantino. Cuestiones de cronología y adscripción cultural, Murcia, Tabularium.

(2013), Análisis bibliométrico de la producción cientifica sobre la pintura rupestre postpaleolitica en España. Arte levantino y pintura esquemática (1907-2010), tesis de doctorado, Murcia, Departamento de Prehistoria, Arqueología, Historia Antigua, Historia Medieval y Ciencias y Técnicas Historiográficas, Universidad de Murcia.

Merton, R. K. (1968), “The Matthew effect in science”, en Science, 199, 55-63.

Miguel Dasit, A. (2003), Estudio bibliométrico de las publicaciones españolas sobre diagnóstico por la imagen (1994-1998), tesis de doctorado, Valencia, Universitat de València.

Molina, J. K.; Muñoz, J. M. y Doménech, M. (2002), "Redes de publicaciones científicas: un análisis de la estructura de coautorías”, en Redes. Revista Hispana para el Análisis de Redes Sociales, 1 (3), Barcelona. Disponible en: http://revista-redes.rediris.es/html-vol1/vol1 _3.htm [Fecha de consulta: 24 de octubre de 2011].

Montes Bernárdez, R. y Cabrera Garrido, J. A. (1992), "Estudio estratigráfico y componentes pictóricos del arte prehistórico de Murcia (Sureste de España)", en Anales de Prebistoria y Arqueología, 7-8, 60-74.

Nicholls, P. T. (1986), "Empirical validation of Lotka's law”, en Information Processing and Management, 22 (5), 417-419.

Osca Lluch, J. y Mateo Marquina, Ma. E. (2003), “Difusión de las revistas españolas de ciencias sociales y humanidades. Acercamiento bibliométrico", en Revista General de Información y Documentación, 13 (1), 115-132.

Otte, E. y Rousseau, R. (2002), "Social networks analysis: a powerful strategy, also for the information sciences", en Journal of Information Science, 28 (6), 441-453.

Over, R. (1982), "Collaborative research and publication in psychology”, en American Psychology, 37, 996-1001.

Pao, M. L. (1982), "Collaboration in computacion musicology", en Journal of the American Society for Information Science, 33 (1), 38 41. 
Pao, M. L. (1985), "Lotka's law: a testing procedure”, en Information Processing E Management, 21 (6), 305-320.

(1986), "An empirical examination of Lotka's law", en Journal of the American Society for Information Science, 37 (1), 26-33.

Price, D. J. de Solla (1963), Big Science, Little Science, New York, Columbia University Press.

- y Gürsey, S. (1976), "Studies in scientometrics: Part I: Transcience and continuance in scientific authorship", en Internationalt Forum on Information and Documentation, 1, 17-24.

Pulgarín, A.; González-Calatrava, I.; Escalona-Fernández, I. y PérezPulido, M. (2003), Estudio bibliométrico de la producción cientifica y tecnológica de la Universidad de Extremadura: análisis de la difusión alcanzada en bases de datos internacionales. Periodo 19912000, Cáceres, Universidad de Extremadura.

__ González-Calatrava, I.; Escalona-Fernández, I. y Pérez-Pulido, M. (2004), Estudio bibliométrico de la producción científica de la Universidad de Extremadura: análisis de la difusión alcanzada en bases de datos nacionales. Periodo 1974-2001, Cáceres, Universidad de Extremadura.

__ Lagar, Ma. P. y Escalona, Ma. I. (2010), “Colaboración científica de la ingeniería química en las universidades españolas”, en Revista General de Información y Documentación, 20, 101-113.

Raisig, L. M. (1960), "Mathematical evaluation of the scientific serial”, en Science, 131, 1417-1419.

Ripoll Perelló, E. (1961), "Los abrigos pintados de los alrededores de Santolea, Teruel”, en Monografías de Arte Rupestre. Arte Levantino, 1, Barcelona, Instituto de Prehistoria y Arqueología de la Diputación Provincial de Barcelona, Werner Gren Foundation for Anthropological Research.

Rodríguez Alcalde, A. L.; San Millán Bujanda, Ma. J.; Sánchez Nistal, J. M. y Chapa Brunet, Ma. T. (1993), "Análisis bibliométrico de Trabajos de Prehistoria: un chequeo a la Prehistoria española de las tres últimas décadas", en Trabajos de Prehistoria, 50, 11-37.

__ Sánchez Nistal, J. M.; Martínez Navarrete, Ma. I. y San Millán Bujanda, Ma. J. (1996), "Análisis bibliométrico de las revistas españolas de Prehistoria y Arqueología en los últimos diez años", en Trabajos de Prebistoria, 53, 37-58.

Roldán García, C. (2009), "Análisis de pigmentos en conjuntos de arte rupestre", en Actas del IV Congreso El arte rupestre del Arco Mediterráneo de la Península Ibérica, Valencia, Instituto Alicantino de Cultura Juan Gil-Albert de la Diputación Provincial de Alicante, 269-277.

(2012), "Contribución de los análisis físico-químicos a la caraterización y conservación del arte rupestre en entornos abiertos”, en Jornadas Técnicas para la gestión del arte rupestre, Patrimonio Mundial, 2012, Alquezar, Huesca, Comarca del Somontano y Ministerio de Educación, Cultura y Deporte, 129-136. 
Rovira Llorens, S. (1994), "Estudio bibliométrico del Boletín de la Asociación de Amigos de la Arqueología", en Boletín de la Asociación de Amigos de la Arqueología, 34, 57-65.

Russell, J. M.; Madera Jaramillo, Ma. J. y Ainsworth, S. (2009), "El análisis de redes en el estudio de la colaboración científica”, en Redes. Revista hispana para el análisis de redes sociales, 17 (2). Disponible en: http://revista-redes.rediris.es/html-vol17/vol17_2.htm [Fecha de consulta: 14 de septiembre de 2011].

Sancho, R. (1990), "Indicadores bibliométricos utilizados en la evaluación de la ciencia y la tecnología. Revisión bibliográfica", en Revista Española de Documentación Científica, 13 (3-4), 842-865.

Shubert, A. y Glänzel, W. (1991), "Publication dynamics: model and indicators”, en Scientometrics, 20 (1), 317-331.

Terrada, M. L. (1971), "España en el panorama internacional de las publicaciones médicas”, en Médula Espinal, 66, 191-198.

(1973), "El 'impacto' internacional de la literatura médica española contemporánea: índice de visibilidad de Platz”, en Médula Espinal, 70, 239-244.

Valderrama, J. C.; González, G.; Valderrama, F. J.; Aleixandre, R. y Miguel, A. (2007), "Redes de coautorías y colaboración institucional en Revista Española de Cardiología”, en Revista Española de Cardiología, 60 (2), 117-130.

Valenciano, J.; Devís, J.; Villamón, M. y Peiró, C. (2010), “La colaboración científica en el campo de las Ciencias de la Actividad Física y el Deporte en España”, en Revista Española de Documentación Cientifica, 33 (1), 90-105.

Zulueta, Ma. A.; Cabrero, A. y Bordons, M. (1999), “Identificación y estudio de grupos de investigación a través de indicadores bibliométricos", en Revista Española de Documentación Científica, 23 (3), 333-347. 